\title{
Implications for Factors Affecting Prevention of Mother-to-Child Transmission of HIV Programs in University Teaching Hospitals in Anambra State
}

\author{
Article by Michael Olugbamila Dada ${ }^{1}$, Ogbodo, Uchechukwu Chibuzo ${ }^{2}$ \\ ${ }^{1}$ HSS and Lab Department, FHI360, Anambra State, $3^{\text {rd }}$ Floor, State Ministry of \\ Health, Awka, Anambra State, Nigeria \\ ${ }^{2} M \&$ E Department, FHI360, Anambra State, $3^{\text {rd }}$ Floor, State Ministry of Health, \\ Awka, Anambra State, Nigeria \\ E-mail: 1'gbamidada25@yahoo.com
}

\begin{abstract}
Background: Vertical Mother-to-child transmission of human immunodeficiency virus (HIV) remains a cause for alarm in the course of new HIV infections in newborns in SubSaharan Africa. Poor utilization of PMTCT services accounts for the high HIV burden recorded in Anambra State of Nigeria. Aiming pregnant women attending antenatal clinics provide a unique opportunity for implementing prevention of mother-to-child transmission (PMTCT) programs against HIV infection of newborn babies.

Objective: This study aimed to investigate obstacles and implications associated with the poor access and utilization of PMTCT services in selected teaching hospitals in Anambra State.

Methods: A descriptive cross-sectional study was employed using interviews with 128 adult pregnant HIV-infected women attending antenatal care clinics of two teaching hospitals in Anambra State of Nigeria. Trained data collectors administered structured questionnaires to collect data on socio-demographic characteristics, knowledge about HIV and PMTCT, satisfaction with service care providers and obstacles to utilization of PMTCT services.

Results: $99 \%$ of the study participants knew that HIV was a deadly virus transmitted through sex and other blood contact routes. $76 \%$ of the participants knew that HIV could be transmitted from mother to child and about 53\% of them actually knew the major ways of MTCT of HIV. $41 \%$ of the participants did not know how HIV could be passed from mother to child. Lack of awareness and knowledge about HCT, late presentation at ANC clinics, low numbers of PMTCT centers within locality of respondents, poor involvement of male partners/spouses and stigma were the main reasons cited for poor utilization of PMTCT programs in the state.

Conclusion: In order to overcome the obstacles highlighted in this study, strong political and economic commitments need to be incorporated in PMTCT service provider delivery. $H I V$ counselling and testing among ANC attendees and creating knowledge/awareness about MTCT of HIV ought to be a priority. Further research should be conducted qualitatively to augment the quantitative data.
\end{abstract}

Keywords: Human immunodeficiency virus, Prevention of mother to child transmission HIV counselling and testing, Antenatal Care

\section{Background}

HIV/AIDS is one of the global pandemics facing the world today. It is acknowledged the world's deadliest without proper care and optimum interventions. In 2009, the United Nations AIDS Program (UNAIDS) reported that 430,000 of the approximately 2.5 million children under the age of 15 living with HIV were newly infected, the majority in sub-Saharan Africa (United Nations Aids Programme, 2010). Many of these children acquired the infection from their mothers during pregnancy, birth, or breastfeeding. Timely administration of antiretroviral drugs to a HIV-positive pregnant woman and her newborn child significantly 
Texila International Journal of Public Health

Volume 5, Issue 1, Mar 2017

reduces the risk of mother-to-child transmission (WHO, 2006). Now recognized as an attainable public health strategy, preventing mother-to-child transmission (PMTCT) has four basic components: (i) prevention of primary infection among women, (ii) prevention of unintended pregnancies among HIV positive women, (iii) provision of specific interventions to reduce the risk of mother-to-child transmission, and (iv) provision of care, treatment and support to HIV infected women, their infants and families (WHO, 2007; WHO, 2010). Providing highly active antiretroviral therapy to a woman will reduce viral replication and viral load during pregnancy, and as a post-exposure prophylaxis, prevent infection in newborns (WHO, 2006; Siegfried et al., 2011; Dabis, 2000).

Interventions to reduce pediatric HIV infection have become readily available worldwide, especially in low and middle-income countries. In 2009, 53\% of HIV-infected pregnant women worldwide received antiretroviral (ARV) drugs to prevent mother-to-child transmission (WHO, 2010). While coverage is increasing in sub-Saharan Africa, ranging from $8 \%$ in some settings to $54 \%$ in others (WHO, 2007), PMTCT programs in the continent are still plagued by multiple problems. For instance, many HIV positive pregnant women still face constraints in accessing ARV drugs because they refuse to participate or are lost to follow-up in existing programs. Health system factors (critical shortage of personnel, lack of skilled attendant at birth, poor infrastructure, and inadequate supply of PMTCT kits) as well as individual and socio-cultural factors (stigma, nonawareness of PMTCT services, lack of spousal and family support, loss to follow-up, negative experiences with hospital staff, the preference for home delivery) have been highlighted as barriers in the literature (Barker et al., 2011; Thielgaard et al., 2011; Chinkonde et al., 2009; Manzi et al., 2005; WHO, 2005). Nigeria, like most countries in sub-Saharan Africa, is experiencing a high prevalence of HIV with about $4.1 \%$ of the adult population living with the virus (NACA, 2011; UNAIDS, 2008) largely due to heterosexual transmission. Besides heterosexual transmission, vertical transmission of HIV from mother-to-child accounts for more than $90 \%$ of pediatric AIDS cases (NACA, 2011). To reduce the number of mother-to-child HIV infections, the governments of various countries have set a goal of universal access and increased the capacity for the delivery of HIV counseling and testing, prevention of mother-to-child transmission, and provision of ARVs by about 2-, 6-, and 8-fold, respectively (UNAIDS, 2008). Despite this increase, the number of women accessing these services is still low. For instance, after more than 5 years since the goal for universal access was established, less than 7,000 HIV positive pregnant women received ARV prophylaxis, representing about $19 \%$ of the annual targets (Federal HIV/AIDS Prevention and Control Office, 2011).

The reasons why HIV positive pregnant women are not accessing PMTCT services or return for follow-up vary from one context to another. Generally however, biological, operational, and local-contextual factors continue to impede the uptake of PMTCT services in many parts of sub-Saharan Africa even when services are available (WHO, 2007; Painter et $a l, 2004)$. To address the problem of low utilization of PMTCT interventions, it is important to highlight and understand unique contextual factors and how they affect the performance of PMTCT programs. The aim of this study was to highlight and describe specific sociocultural, health system and operational barriers that contribute to the low uptake of PMTCT services in Anambra State of Nigeria, a region in the country ranked $4^{\text {th }}$ for the HIV/AIDS burden of $8.7 \%$ (HSS, 2010) and a high risk rate for mother-to-child transmission and, understand why the transmission rate from mother to child has remained high amongst the eastern states of Nigeria. Understanding first the obstacles that affect the success of PMTCT and possible implications for these barriers would help develop new strategies to achieve high uptake, create alternate accessibility routes for the program, if Nigeria were to meet the United Nations Global Plan for eliminating new HIV infections and sustaining these goals. 


\section{Materials and methods}

\section{Study design}

A cross-sectional descriptive method that applied quantitative surveys was used to triangulate findings.

\section{Study setting and population}

Anambra State is situated in South-East zone geopolitical zone of Nigeria with Awka as the state capital. Ethnically, Anambra state is $98 \%$ of Igbo population and $2 \%$ LGAs. The state is bounded in the northeast by Enugu state, in the east by Enugu and Abia states, in the west by Delta while in the south and northwest by Imo and Kogi states respectively. Administratively, the state is divided into 21 Local Government Areas, 235 health districts, 330 wards and 177 communities. Anambra state has an annual growth rate of about $2.80 \%$ and the state was projected to have approximately 4,984,127 people at the end of 2012. It is a densely populated state with about 1,500 to 2,000 persons $/ \mathrm{km}$ (Anambra state, 2013; FMOH, 2010). There are 1,085,949 women of reproductive age (WRA) (15-49 years of age), while the children under five years and below one year of age are 966,749 and 193,350, respectively. There are about 1,485 health facilities in the state, $72 \%$ of which are private. Within the public sector, there are two tertiary health facilities-(one owned by federal and one owned by the state government and 31 public secondary health care facilities that are managed by the Anambra state government through the State Hospital Management Board of the State Ministry of Health (SMOH).

Nnamdi Azikiwe University Teaching Hospital (NAUTH) located in Nnewi and Anambra State University Teaching Hospital (ANSUTH) in Awka were selected for this study because of presence of comprehensive PMTCT services. This facility-based cross-sectional study was conducted among pregnant HIV-infected women attending ANC clinics in these two comprehensive hospitals. Women of reproductive age (15-49 years) constitute about $22 \%$ of the total population while $2.4 \%$ of the population is estimated to be pregnant women.

\section{Sample size and sampling procedures}

The study used quantitative data collection methods in two selected comprehensive facilities offering large-scale PMTCT services. The study population included pregnant women who received the services of ANC clinics of the selected health institutions. Two opted out of the study. The sample size for this study was determined using an appropriate statistical formula for estimating sample size in health studies: $\mathrm{n}=\mathrm{Z2Pq} / \mathrm{d}^{2}$

Where:

$\mathrm{n}=$ the required sample size;

$\mathrm{Z}=$ the coefficient of $\mathrm{Z}$ statistic (the standard normal deviate at $95 \%$ confidence level obtained from the standard normal distribution table);

$\mathrm{P}=$ prevalence rate in $\%$;

$\mathrm{q}=100-\mathrm{P}$

$\mathrm{d}=$ the desired precision of the study or sampling error tolerated in $\%$.

Using a prevalence rate $\mathrm{P}$ of $9.2 \%$ obtained from a previous similar study in Anambra state, a confidence limit of $95 \%(\mathrm{~d}=5 \%)$, and $\mathrm{Z}$ of 1.96 , the calculated sample size, $n$ will be 130. Two pregnant women opted mid-way into the study, making the study participants to be 128.

\section{Data collection}

Data collection commenced in February 2016 after relevant ethical approvals were obtained and ended in August of the same year. All pregnant women attending the ANC clinic who consented to the interview and met the inclusion criteria participated in the study. A pre-tested structured questionnaire was used for data collection. The questionnaire mainly consisted of multiple response sets with some open-ended questions addressing socio- 
Texila International Journal of Public Health

Volume 5, Issue 1, Mar 2017

demographic characteristics, knowledge about the MTCT of HIV, ANC visit, HCT, partner's HIV testing status, privacy and confidentiality and satisfaction with the services. Four trained data collectors administered a questionnaire using face-to-face exit interviews. Completed questionnaires, carefully examined for missing values by the researcher were submitted to the statistician for analysis.

\section{Data analysis}

Statistical analysis was done using IBM SPSS Statistics version 21 to analyze quantitative data. Characteristics of the mothers were summarized and presented using proportions, means, medians, frequency tables or cross-tabulations for continuous variables and proportions for categorical variables. Chi square $\left(X^{2}\right)$ test was performed to test for statistical significance between proportions for the cross tabulated variables. Level of significance was set at $p<0.05$.

\section{Ethical approval}

Ethical approval and clearance for the study was obtained from the Research Ethics Committees of both comprehensive facilities where large scale PMTCT services are offered. Consent to conduct the study was also obtained from the health facilities. Individual verbal informed consent was obtained from every study participant who agreed to participate in the study based on the study inclusion criteria of having attended ANC clinic more than once and between 18-49 years. Strict confidentiality and anonymity practices were followed in the administration of the questionnaires for all clients both during and after data collection.

\section{Results}

\section{Socio-demographic characteristics of respondents}

The final sample for quantitative data analysis included 128 pregnant HIV-infected women, who consented to participate in the study. A response rate of $99 \%$ was recorded. $65 \%$ $(n=83)$ of the respondents were ANC attendees at NAUTH while $35 \%(n=45)$ of the respondents were from ANSUTH. Their age ranged from 18 to 49 years with a mean \pm SD and median ages of $25.4 \pm 4.5$ years and 25 years respectively. $70 \%$ of the study participants resided in urban areas, $84 \%$ were married, $57 \%$ had formal education with $40 \%$ of them having secondary and tertiary education and $51 \%$ were employed.

Table 1. shows the sociodemographic characteristics of the 128 mothers

\begin{tabular}{|c|c|c|c|}
\hline \multirow[t]{2}{*}{ Variable } & \multicolumn{2}{|c|}{ Respondents by Health Facility } & \multirow[t]{2}{*}{ Total $(\mathrm{n}, \%)$} \\
\hline & ANSUTH & NAUTH & \\
\hline \multicolumn{4}{|c|}{ Maternal age } \\
\hline $18-24$ & $14,31 \%$ & $32,39 \%$ & $46,36 \%$ \\
\hline $25-34$ & $22,49 \%$ & $43,52 \%$ & $65,51 \%$ \\
\hline $35-44$ & $9,20 \%$ & $8,9 \%$ & $17,13 \%$ \\
\hline \multicolumn{4}{|l|}{ Location } \\
\hline Urban & $34,76 \%$ & $55,66 \%$ & $89,70 \%$ \\
\hline Rural & $11,24 \%$ & $28,34 \%$ & $39,30 \%$ \\
\hline \multicolumn{4}{|c|}{ Marital Status } \\
\hline Married & $40,88 \%$ & $68,82 \%$ & $108,84 \%$ \\
\hline Single & $5,11 \%$ & $15,18 \%$ & $20,16 \%$ \\
\hline Separated & $0,0 \%$ & $0,0 \%$ & $0,0 \%$ \\
\hline Widowed & $0,0 \%$ & $0,0 \%$ & $0,0 \%$ \\
\hline \multicolumn{4}{|c|}{ Level of Education } \\
\hline $\begin{array}{l}\text { No formal } \\
\text { education }\end{array}$ & $16,36 \%$ & $29,35 \%$ & $40,31 \%$ \\
\hline Primary & $9,20 \%$ & $24,29 \%$ & $36,17 \%$ \\
\hline
\end{tabular}




\begin{tabular}{|l|l|l|l|}
\hline Secondary & $10,22 \%$ & $15,18 \%$ & $22,17 \%$ \\
\hline Tertiary & $10,22 \%$ & $15,18 \%$ & $30,23 \%$ \\
\hline Employment status \\
\hline Employed & $29,64 \%$ & $36,43 \%$ & $65,51 \%$ \\
\hline Unemployed & $16,36 \%$ & $47,57 \%$ & $63,49 \%$ \\
\hline
\end{tabular}

Nauth: Nnamdi Azikiwe University Teaching Hospital; ANSUTH: Anambra State University Teaching Hospital

\section{Knowledge of respondents about MTCT of HIV and PMTCT services}

Almost all study participants (99\%) had knowledge of HIV to be a deadly sexually transmitted viral infection that can be contracted through blood contact. $76 \%$ of the participants knew that HIV could be transmitted from mother to child and about $53 \%$ of them actually knew the major ways of MTCT of HIV. $41 \%$ of the participants did not know how the transmission occurs raising concern about creating awareness and educating women of reproductive age and people in general about HIV transmission from mother to child. Respondents in ANSUTH (84\%) had better understanding of what PMTCT is all about and had readily accessible PMTCT services in their area (about 84\%).

Table 2. Shows the knowledge of respondents about PMTCT services

\begin{tabular}{|c|c|c|c|}
\hline \multirow[t]{2}{*}{ Variable } & \multicolumn{2}{|c|}{$\begin{array}{l}\text { Respondents by Health } \\
\text { Facility }\end{array}$} & \multirow[t]{2}{*}{ Total (n, \%) } \\
\hline & ANSUTH & NAUTH & \\
\hline \multicolumn{4}{|l|}{ Understanding of HIV } \\
\hline A deadly disease & $10,22 \%$ & $3,4 \%$ & $13,10 \%$ \\
\hline $\begin{array}{l}\text { An immunodeficiency } \\
\text { disease }\end{array}$ & $8,18 \%$ & $24,29 \%$ & $32,25 \%$ \\
\hline $\begin{array}{l}\text { A sexually transmitted } \\
\text { disease }\end{array}$ & $22,49 \%$ & $31,37 \%$ & $53,41 \%$ \\
\hline $\begin{array}{l}\text { An infection that can } \\
\text { contracted through blood }\end{array}$ & $5,11 \%$ & $25,30 \%$ & $30,23 \%$ \\
\hline \multirow{2}{*}{\multicolumn{4}{|c|}{\begin{tabular}{l|l} 
Don't know & \\
HIV can be transmitted from mother to child
\end{tabular}}} \\
\hline & & & \\
\hline \multicolumn{2}{|c|}{$\begin{array}{l}\text { HIV can be transmitted from mother to child } \\
\begin{array}{l|l|l}\text { Yes } & 30,67 \% & 67,81 \%\end{array}\end{array}$} & $67,81 \%$ & $97,76 \%$ \\
\hline No & $12,27 \%$ & $10,12 \%$ & $22,17 \%$ \\
\hline Don't know & $3,6 \%$ & $6,7 \%$ & $9,7 \%$ \\
\hline \multicolumn{4}{|c|}{ Time of transmission from mother to child } \\
\hline During pregnancy & $12,27 \%$ & $10,12 \%$ & $22,17 \%$ \\
\hline During labour & $9,20 \%$ & $8,10 \%$ & $17,13 \%$ \\
\hline During breastfeeding & $6,13 \%$ & $23,28 \%$ & $29,23 \%$ \\
\hline Other & $2,4 \%$ & $17,20 \%$ & $19,15 \%$ \\
\hline Don't know & $16,36 \%$ & $25,30 \%$ & $41,32 \%$ \\
\hline \multicolumn{4}{|c|}{ Understanding of PMTCT } \\
\hline $\begin{array}{l}\text { Prevention of HIV from } \\
\text { mother to child }\end{array}$ & $38,84 \%$ & $51,61 \%$ & $89,70 \%$ \\
\hline Don't know & $7,16 \%$ & $32,39 \%$ & $39,30 \%$ \\
\hline \multicolumn{4}{|c|}{ Availability of PMTCT services in your area } \\
\hline Yes & $38,84 \%$ & $77,93 \%$ & $115,90 \%$ \\
\hline No & $7,16 \%$ & $6,7 \%$ & $13,10 \%$ \\
\hline
\end{tabular}

Nauth: Nnamdi Azikiwe University Teaching Hospital; ANSUTH: Anambra State University Teaching Hospital 
Texila International Journal of Public Health

Volume 5, Issue 1, Mar 2017

\section{Barriers to access and utilization of PMTCT services}

The findings of the study highlighted as obstacles to successful access, utilization and uptake of PMTCT services by the study participants, the following: the way health workers treat the mothers (mistreatment), the time taken to get ANC service (long wait time, long wait time to get laboratory tests and obtain results), long walking distance to facility, getting off work, and late presentation to ANC for HIV testing and counselling were among the barriers that contribute to the low utilization of ANC/PMTCT services in the state.

Most study participants (80\%) were content with the level of service provided by the health workers as they affirmed that they were knowledgeable about their work and showed competence. However, some cited hostile attitude towards them and disaffection from the health workers. Cost, convenience, fear of stigma and discrimination were stated as reasons for dropping out of PMTCT services even when informed of their HIV-positive status. In addition, tired of taking the drugs was identified as a major obstacle to keeping up with the PMTCT schedule.

Low utilization of PMTCT programs in the state was also attributed to the fact that male partners showed little or no concern for health issues. This was seen in most of the study participants making decisions for PMTCT services without their partners/spouses. As deduced by the study, the men believed in being in a steady healthy state and needed no services of the hospital in any form. It was also due to a lack of financial commitment to the health of the mother and child during pregnancy, by the male partners.

The result findings showed constraints stratified at individual, family and facility levels. Other limitations included economic and work-related.

\section{Discussion}

In Africa, where about $90 \%$ of the world's new paediatric HIV infections occur, attaining high PMTCT coverage has the potential to contribute substantially to eradicating infant HIV infection globally. In this study, we found a number of economic, health system and family factors hindering utilization and uptake of PMTCT services in Anambra State. To address/mitigate new infections in young children, the factors need to be checked in the face of achieving the global targets set by the United Nations for reducing HIV MTCT, for which Nigeria accounts $30 \%$ of the global PMTCT gaps.

Financial constraint was found to be a major barrier of PMTCT uptake in this study. Women defaulted ANC attendance because of lack of money. Often, they have to choose between coming to ANC and pursuing other financially yielding ventures. Also, the husbands of these women could not provide transport fees, and coming for ANC by these HIV-infected women is a common cause of family dispute. With the gradual withdrawal of financial assistance by the implementing partners, such as reimbursements of transport costs and abolition of users fees associated with institutional care and delivery services to HIV-infected pregnant women for ANC attendance may become increasingly impossible. Therefore, the need for couples to be educated to see PMTCT services as a family priority and a positive way of life cannot be overemphasized. Families and most especially male partners should be encouraged to give priorities to provision of transport fees for ANC attendance in the midst of competing financial obligations (Deressa et al, 2014).

The poor quality of PMTCT services experienced by the HIV women was another barrier identified in this study as the mothers complained of long wait times, judgmental and poor staff attitude. While recruitment of more staff could reduce the burden of work load on health workers, the financial implication may not make this option an easy and immediate solution; therefore, efforts should be geared toward improving the efficiency of the existing workers via training and retraining on issues of PMTCT services. As earlier suggested by Barker et al (2011),the health system efficiency can be optimized by close examination of the clinic flow, documentation of requirements, and other logistical improvements which can maximize the efficiency of services and decrease women's waiting times even with the existing staff 
strength. Shifting tasks among health workers may be another way of maximizing staff roles where feasible for a smoother service delivery (Zachariah et al., 2009).

Stigma and discrimination was another major barrier identified in this study. This barrier was general as it affected the uptake of PMTCT services at all levels of the cascade. This is in line with studies done by Link \& Phelan, 2001; UNAIDS, 2005; Nguyen et al., 2008). Stigma and discrimination was responsible for the following identified reasons for less than optimized utilization of PMTCT programs in the state. These included why mothers did not come for HIV testing; why mothers did not disclose HIV-positive status to their male partners; why mothers did not want to take ARV medicine in the presence of friends and family members either at home, elsewhere or when they travelled; why mothers did not want to administer NVP to their infants in the presence of family members, in-laws and friends; why mothers did not want to come for ANC visits; why mothers will breastfeed their babies outside their homes but will revert to replacement feeding at home; and partly the reason mothers preferred home delivery by TBAs (Deressa et al., 2014; Anigilaje et al., 2015).

The findings of the study have several implications pertinent to the success of PMTCT programs and impact of HIV burden in the state. These include increased socio-economic outcomes for the state since women are known to be involved in different walks of life. Others are improved health outcomes for mother and child and reduced HIV burden in the state. Spousal support and encouragement, when available tend to strengthen the system for better access and use of PMTCT services. In Deressa et al. (2004), the support of women by husbands in ANC has several implications for uptake of PMTCT and these include the high rate of partner counselling and testing and less drop-out cases of pregnant women in PMTCT services. Studies by Chikonde et al (2009) revealed that one of the reasons women drop out of these programs is because of male partners' reaction to HIV-seropositive status. Similar to the present findings, male partners' reaction to HIV status contribute to low throughput in PMTCT interventions and high rates of result disclosure in the state (Kasenga et al., 2008; Medley et al., 2004; Gari et al., 2009; Kelley et al., 2011).

Some of the study participants recommended that government should do more to encourage participation by HIV-seropositive pregnant mothers by creating awareness of the program and instituting free $\mathrm{MNCH}$ programs. Where possible, a reward system should be put in place at the facilities to increase ANC attendance. Also, anti-discrimination acts available at the federal level should be enforced at all levels of government-owned facilities to ensure wide PMTCT acceptance. Mother-to-mother support groups was advocated to be restored by the study participants. This is worthwhile as women tend to connect with those who have experiences in what they are going through and desire to be emotionally nurtured. More strategic efforts need to come in the area of male partner involvement, couple testing and counselling and promoting PMTCT.

\section{Conclusion}

Late presentation to ANC, stigma and discrimination experienced by HIV-infected mothers, financial constraints, weak health system orchestrated by poor staff attitude, nonparticipatory roles of male partners, were the identified major barriers against effective PMTCT interventions in the study setting. The recommendations suggested by the participants of the study, if properly used in program and policy planning can go a long way to improving quality of PMTCT utilization in the state.

\section{Recommendations}

The researcher suggests a qualitative approach to the study, for both health service providers and ANC attendees to augment the quantitative data obtained in the study area. For non-government organization interventions to record success in PMTCT thematic area of HIV prevention, care and treatment, the researcher recommends an integration of family, community, government and legal mechanisms of control at facility level for effective and efficient delivery of services. To that effect, indicators tracking success at different levels 
Texila International Journal of Public Health

Volume 5, Issue 1, Mar 2017

would need to be developed to measure impact of receptiveness of PMTCT interventions at these levels.

\section{References}

[1]. Barker, P.M., Mphatswe, W. and Rollins, N. (2011). "Antiretroviral drugs in the cupboard are not enough: the impact of health systems' performance on mother-to-child transmission of HIV," Journal of Acquired Immune Deficiency Syndromes, Vol. 56, No. 2, pp. e45-e48.

[2]. Chinkonde, J.R., Sundby, J. and Martinson, F. (2009). "The prevention of mother-to-child HIV transmission programme in Lilongwe, Malawi: why do so many women drop out," Reproductive Health Matters, Vol. 17, No. 33, pp. 143-151.

[3]. Dabis, F., Newell, M.L., L. Fransen, L. et al. (2000). "Prevention of mother-to-child transmission of HIV in developing countries: recommendations for practice," Health Policy and Planning, vol. 15, no. 1, pp. 34-42.

[4]. Deressa, W., Seme, A., Asefa, A., Teshome, G. and Enqusellassie, F. (2014). Utilization of PMTCT services and associated factors among pregnant women attending antenatal clinics in Addis Ababa, Ethiopia. BMC Pregnancy and Childbirth Vol. 14 p.328-341.

[5]. Eshleman, S.H., Mracna, M., Guay, L., et al. (2001). Selection and fading of resistance mutations in women and infants receiving nevirapine to prevent HIV-1 vertical transmission (HIVNET 012). AIDS, Vol. 15:1951-1957.

[6]. Federal HIV/AIDS Prevention and Control Office (2011). In Multi-sectoral HIV/AIDS Response Annual Monitoring and Evaluation Report 202 EFY.

[7]. Federal Ministry of Health (2010). National HIV Sero-Prevalence Sentinel Survey. FMOH Abuja Nigeria.

[8]. Federal Ministry of Health. (2003). National HIV/AIDS and Reproductive Health Survey (NARHS).

[9]. Gari,T., Habte, D. and Markos, E. (2009). HIV positive status disclosure to sexual partner among women attending ART clinic at Hawassa University Referral Hospital, SNNPR, Ethiopia. Ethiop J Health Dev. 24 (1): 9-14.

[10]. Kasenga F, Hurtig A, Emmelin M (2008). HIV-positive women's experiences of a PMTCT programmeme in rural Malawi. Midwifery.

[11]. Kelley, A.L., Karita, E., Sullivan, P.S., Katangulia, F., Chomba, E., Carael, M., Telfair, J., Dunham, S.M., Vwalika, C.M.,Kautzman, M.G., Wall, K.M. and Allen, S.A. (2011). Knowledge and perceptions of couples' voluntary counseling and testing in urban Rwanda and Zambia: a crosssectional household survey. PLoS One. 6(5).

[12]. Lallement, M. (2005). Response to the therapy after prior exposure to nevirapine. 3rd IAS Conference on HIV Pathogenesis and Treatment, Rio de Janeiro, Brazil, July 24-27.

[13]. Link B, Phelan J. (2001). On stigma and its public health implications. Paper presented at: Stigma and Global Health: Developing a Research Agenda; Bethesda, MD. Washington: National Institutes of Health.

[14]. Manzi, M., Zachariah, R., Teck, R. et al., (2005). "High acceptability of voluntary counselling and HIV-testing but unacceptable loss to follow up in a prevention of mother-to-child HIV transmission programme in rural Malawi: scaling-up requires a different way of acting," Tropical Medicine and International Health, Vol. 10, No. 12, pp. 1242-1250.

[15]. Medley, A., Garcia-Moreno, C., McGill, S. (2004). Rates, barriers and outcomes of HIV serostatus disclosure among women in developing countries: Implications for prevention of mother-to-child transmission programmes. Bull World Health Organ. 82: 299-307.

[16]. Mofenson, L.M. (2003). Advances in the prevention of vertical transmission of human immunodeficiency virus. SeminPediatr Infect Dis, Vol 4(4), p. 295-308.

[17]. Mofenson, L.M., Lambert, J.S., Stiehm, E.R., et al. (1999). Risk factors for perinatal transmission of human immunodeficiency virus type 1 in women treated with zidovudine. N Engl J Med, Vol. 341 p.385-393.

[18]. National Agency for the Control of AIDS (2011). Factsheet 2011: Update on the HIV/AIDS Epidemic and Response in Nigeria. 
[19]. National Agency for the Control of AIDS (2012). Global AIDS Response Country Progress Report: Nigeria GAPR 2012.

[20]. National Agency for the Control of AIDS (2013). President's Comprehensive Response Plan for HIV/AIDS in Nigeria.

[21]. Nguyen, T.A., Oosterhoff, P., Ngoc, Y.P., Wright, P. and Hardon, A. (2008). Barriers to access prevention of mother-to-child transmission for HIV-positive women in a well-resourced setting in Vietnam. AIDS Res Ther 17:5-7.

[22]. Painter, T.M., Diaby, K.L., Matia, D.M., et al. (2004). "Women's reasons for not participating in follow up visits before starting short course antiretroviral prophylaxis for prevention of mother to child transmission of HIV: qualitative interview study," British Medical Journal, Vol. 329, No. 7465, pp. $543-546$.

[23]. Siegfried, N., van der Merwe, L., Brocklehurst, P. and Sint, T.T. (2011). "Antiretrovirals for reducing the risk of mother-to-child transmission of HIV infection," Cochrane Database of Systematic Reviews, no. 7, p. CD003510.

[24]. Theilgaard, Z.P., Katzenstein, T.L., Chiduo, M.G. et al., (2011). "Addressing the fear and consequences of stigmatization - a necessary step towards making HAART accessible to women in Tanzania: a qualitative study," AIDS Research and Therapy, Vol. 8, No. 1, p. 28.

[25]. United Nations AIDS Program (2010). http://www.unaids.org/globalreport/Global_report.htm [26]. United Nations AIDS Program (2008). Epidemiological Fact Sheet on HIV and AIDS: Core Data on Epidemiology and Response. Ethiopia.

[27]. UNAIDS (2005). HIV-related stigma, discrimination and human rights violations: case studies of successful programs.

[28]. World Health Organization (2005). The World Health Report, Geneva, Switzerland.

[29]. World Health Organization (2006). Antiretroviral Drugs for treating Pregnant women and preventing infection in Infants: Towards Universal Access: Recommendations for a Public Health Approach, WHO, Geneva, Switzerland.

[30]. World Health Organization (2007). Prevention of Mother to Child Transmission (PMTCT). Briefing note, Department of HIV/AIDS.

[31]. World Health Organization (2010).New guidance on prevention of mother-to-child transmission of HIV and infant feeding in the context of HIV.

[32]. World Health Organization (2010). "Towards Universal Access Progress Report.

[33]. Zachariah, R., Ford, N., Philips, M., et al. (2009). Task shifting in HIV/AIDS: Opportunities, challenges and proposed actions for sub-Saharan Africa. Trans R Soc Trop Med Hyg. 103:549-558. 